\title{
DESIGN OF TRAFFIC INTERSECTION AT MOOLAPATTARAI IN ERODE CITY
}

\author{
S. LOGESWARAN \& S. ELAVARASAN
}

Assistant Professor, Department of Civil Engineering,

KPR Institute of Engineering and Technology, Arasur, Coimbatore, Tamil Nadu, India

\begin{abstract}
Transport is the one which gives a major economical source for all the countries. In the 21st century, life without transport cannot be imagined. Traffic congestion is a major problem due to the unexpected growth of private vehicles in a country. India is also a part of that problem. Project work is to master the art of analysis and design the road intersection. The study area is Moolapattarai Junction in Erode City where the traffic congestion is more. A video graphic survey is conducted to analyze the traffic at the intersection and a traffic roundabout with island is designed accordingly based on the IRC.
\end{abstract}

KEYWORDS: Intersection, Design Speed, PCU \& Rotary

Received: Mar 03, 2019; Accepted: Mar 23, 2019; Published: Apr 19, 2019; Paper Id.: IJAERDJUN20192

\section{INTRODUCTION}

An intersection is a place where two or more roads meet at the same place. It is a complex area on a highway, especially in cities. So, proper design of intersection makes the smooth flow of traffic. The area is mainly designed to turn the vehicle into different directions with high safety. It also ensures the safe and efficient movement of traffic with a reduction in accident rate.

\subsection{Objective of the Study}

- To select an uncontrolled intersection which operates with pedestrians, bicycle, cars, buses, and trucks simultaneously.

- To collect appropriate data for the intersection.

- To analyze the collected data.

- To describe several fundamental aspects of intersection design including managing multimodal conflicts, sight distance, layout, etc.

- To provide general principles, considerations and design guidelines for key intersection components.

- To suggest suitable measures for the intersection to control the flow of vehicles

\section{STUDY AREA}

An uncontrolled intersection in Moolapattarai, Erode City was chosen as a study area for this study. It is a four-way skewed Intersection type junction since the roads intersect at an angle less than 75 degrees. The developed town Moolapattarai is located at the junction of Karungalpalayam, Erode bus stand, Bazaar Street and much temple areas. The traffic flow is heavy in this area $\&$ mainly composed of buses $\&$ two wheelers because of 
the presence of bus stand and also paper mills, schools, Colleges that are located nearby. In order to minimize traffic congestion \& reduce the risk of accident in that area, it was planned to design the intersection and regulate the traffic flow in an orderly way. The satellite image of the intersection was shown in Figure 2.1

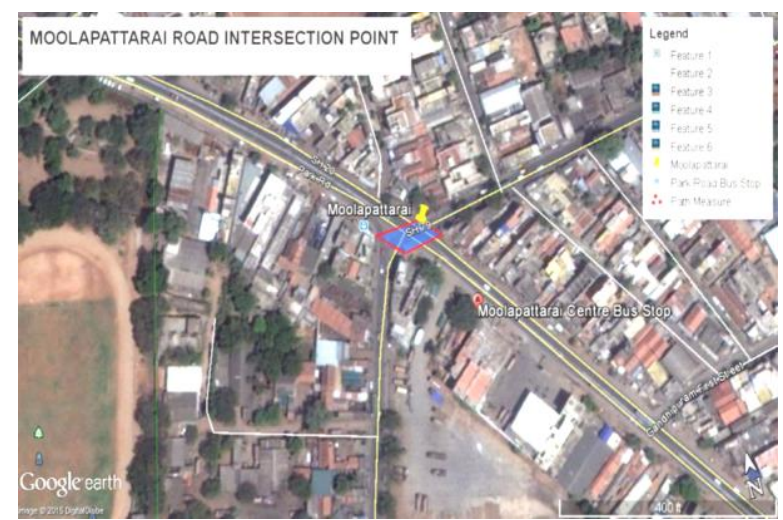

Figure 2.1: Moolapattarai Intersection

\section{DATA COLLECTION}

\subsection{Video Graphic Surveying}

Traffic volumes can be counted by viewing videotapes recorded with a camera collection at the site. A digital clock in the video image can prove useful in noting time intervals. Videotaping is not a cost-effective option in most situations. The traffic count was done manually by looking at the videos for every 15 minutes from start to end of the video graphic data collected. This counted data was used for PCU value findings and peak hour calculation based on which the capacity of the intersection was calculated. Figure 3.1 shows the image of Moolapattarai junction.

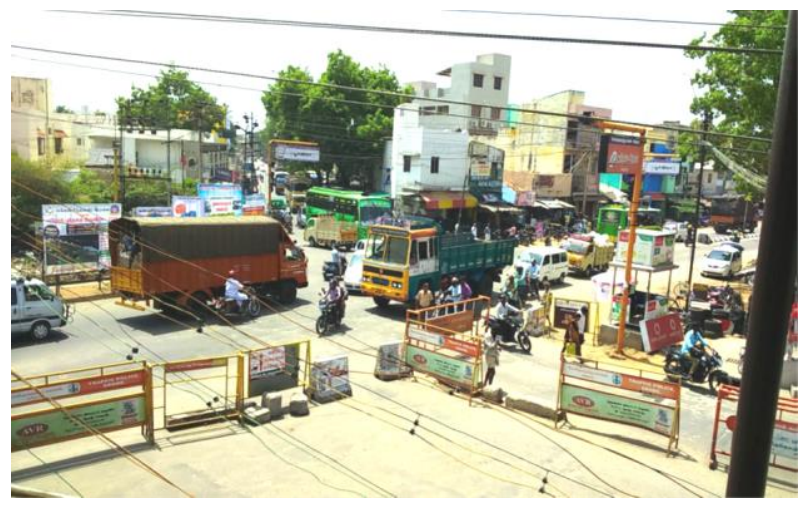

Figure 3.1: Video Graphic Surveying

\section{DATA ANALYSIS}

\subsection{Peak Hour}

Based on the video graphic survey the count of each individual vehicle type (i.e.: Car, Bus, Truck, etc.,.) in each direction for every 15 minutes was taken. The traffic volume was calculated in one common PCU unit. According to IRC SP 41:1994 each type of vehicles carries different PCU values (For e.g.: BUS=3). The count of each type of vehicles was multiplied with their respective PCU values. Then the sum of all PCU values for different type of vehicles was calculated at every 15 minutes. The total PCU values in the left turn movement and right turn movement at every 15 minutes was also calculated. Maximum PCU values obtained in the one hour is called peak hour. The PCU values for each one hour from 
morning 8.00 a.m. to evening at 6.00 p.m. were calculated. The maximum PCU value was obtained as 3780.5 PCU/hour at evening 5.00 p.m. to 6.00 p.m.

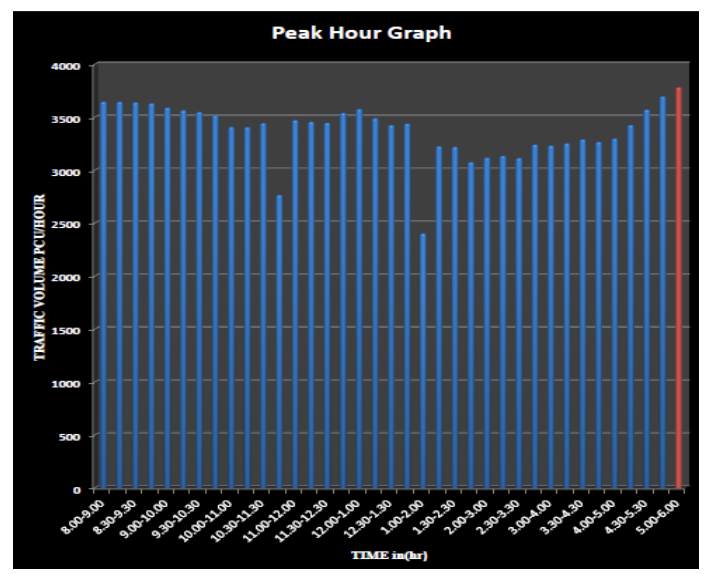

Figure 4.1: Peak Hour Graph

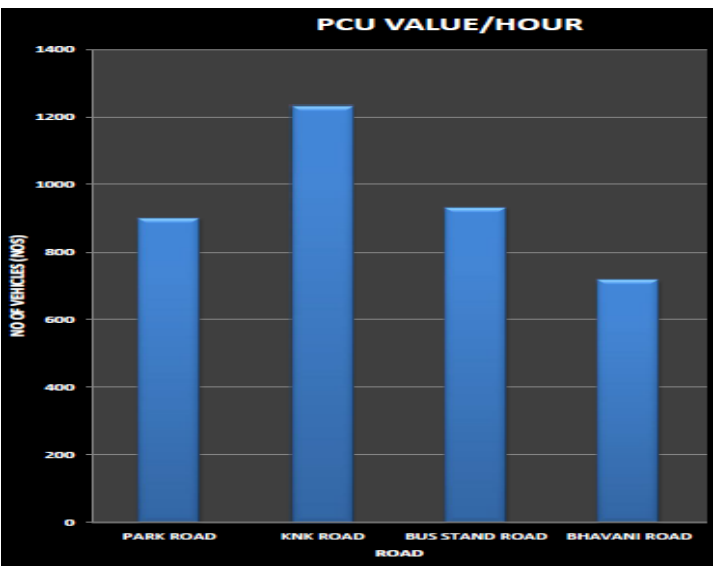

Figure 4.2: PCU Value for Peak Hour of Individual Road



Figure 4.3: Vehicle Composition for Peak Hour

\section{DESIGN OF ROTARIES}

Rotary is an at-grade intersection used for smooth movement of turning of vehicles coming from various places to turn into their respective directions. 


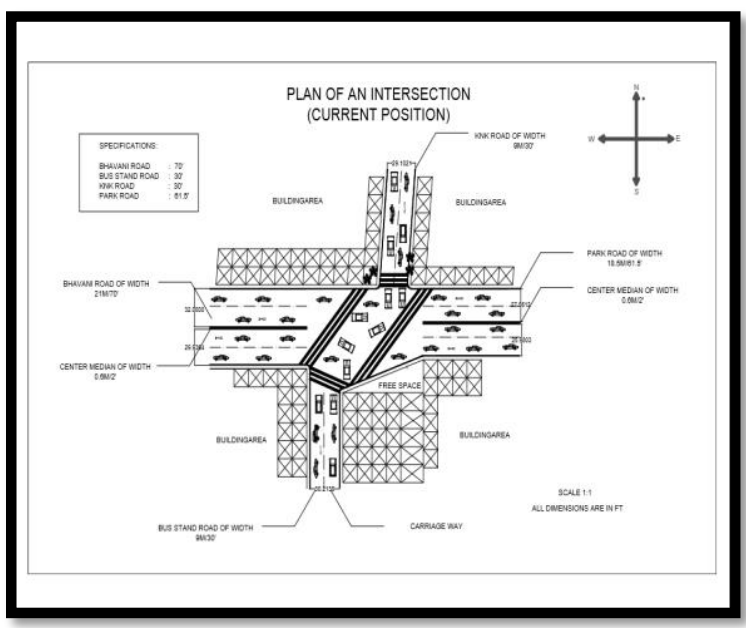

Figure 5.1: Moolapattarai Intersection

\section{RESULT ANALYSIS}

\subsection{Design Details of an Intersection}

Table 6.1: Bus Stand Road

\begin{tabular}{|c|c|}
\hline Entry width & $18.2 \mathrm{~m}$ \\
\hline Exit width & $27.3 \mathrm{~m}$ \\
\hline Weaving length & $16.8 \mathrm{~m}$ \\
\hline Weaving width & $22.2 \mathrm{~m}$ \\
\hline Circular width & $11.1 \mathrm{~m}$ \\
\hline
\end{tabular}

Table 6.2: Bhavani Road

\begin{tabular}{|c|c|}
\hline Entry width & $9.9 \mathrm{~m}$ \\
\hline Exit width & $13.2 \mathrm{~m}$ \\
\hline Weaving length & $35.1 \mathrm{~m}$ \\
\hline Weaving width & $14.7 \mathrm{~m}$ \\
\hline Circular width & $17.1 \mathrm{~m}$ \\
\hline
\end{tabular}

Table 6.3: Park Road

\begin{tabular}{|c|c|}
\hline Entry width & $13.2 \mathrm{~m}$ \\
\hline Exit width & $27.6 \mathrm{~m}$ \\
\hline Weaving length & $15.9 \mathrm{~m}$ \\
\hline Weaving width & $21.3 \mathrm{~m}$ \\
\hline Circular width & $13.2 \mathrm{~m}$ \\
\hline
\end{tabular}


Table 6.4: KNK Road

\begin{tabular}{|c|c|}
\hline Entry width & $10.8 \mathrm{~m}$ \\
\hline Exit width & $12.6 \mathrm{~m}$ \\
\hline Weaving length & $32.7 \mathrm{~m}$ \\
\hline Weaving width & $14.4 \mathrm{~m}$ \\
\hline Circular width & $16 \mathrm{~m}$ \\
\hline
\end{tabular}

\subsection{Carriageway Width}

- At KNK \& Bus stand Road (Two lanes) for an average width of $10 \mathrm{~m}$, the entry radius, and exit radius was given as $15 \mathrm{~m}$.

- At Bhavani \&Park Road (Four lanes) for an average width of $20 \mathrm{~m}$, the entry radius and exit radius was given as $15 \mathrm{~m}$.

\subsection{Entry and Exit Angle}

- Entry angle provided as 60o as per IRC 65: 1976.

- $\quad$ Exit angle provided as 30o as per IRC 65: 1976.

\subsection{Design Speed}

As per IRC SP 41:1994 Table 4.1 and 4.2,

- Minimum design speed in built-up area is $40 \%$ of maximum approach speed.

- Maximum design speed in built-up area is $60 \%$ of maximum approach speed.

- In this project, the road type is SH (State Highways) and plain terrain. The maximum approach speed for this type of road is $80 \mathrm{kmph}$. Therefore the design speed was considered as $30 \mathrm{kmph}(40 \%$ of $80 \mathrm{kmph})$.

\subsection{Dimensions and Turning Radius of the Design Vehicle}

- Truck: $\mathrm{B}=2.58 \mathrm{~m} \mathrm{~L}=9 \mathrm{~m} \mathrm{R}=1.8 \mathrm{~m}$ for rear and 12.8 for front

- Car: $\mathrm{B}=2.1 \mathrm{~m} \mathrm{~L}=5.7 \mathrm{~m} \mathrm{R}=4.5 \mathrm{~m}$ for rear and 7.3 for front

- Maximum height of vehicle as $4.75 \mathrm{~m}$

- Minimum height of vehicle as $3.8 \mathrm{~m}$

- Maximum width of the vehicle as $2.5 \mathrm{~m}$ 


\subsection{Sight Distance}

- Intermediate Sight Distance : $240 \mathrm{~m}$

- $\quad$ Stopping Sight Distance : $120 \mathrm{~m}$

- Overtaking Sight Distance : $470 \mathrm{~m}$

- $\quad$ For $80 \mathrm{kmph} 180 \mathrm{~m}$ visibility sight distance was provided.

Note: All the above values are given as per IRC SP41 (1994).

\subsection{Area of an Intersection}

Area of an intersection- $2816.70 \mathrm{~m}^{2}$

\section{DESIGN DETAILS OF ROTARY}

- Type of Rotary: Circular Type. Circular type is chosen due to twelve movements at the intersection. The design movements of traffic may be complicated in future so in order to avoid such kind of problems provided this type of rotary in this study and movements and turning radius at the rotary may be easy by adopting this type.

- A diameter of Central Island: $15 \mathrm{~m}$ the minimum diameters of the intersection are varies from intersection to intersection. For this study, we provide $15 \mathrm{~m}$ for the extended area of an intersection.

- Divisional island: $\mathrm{L}=10 \mathrm{~m} \& \mathrm{~B}=5 \mathrm{~m}$ (Triangular shape)

- The capacity value of Rotary: 4980PCU/hour. It is calculated from the formulae. This value may be sufficient for the next one decay for handling the traffic conditions at the intersection. Figure 7.1, 7.2 \& 7.3 shows the area details and designed Moolapattarai intersection.



Figure 7.1 Design of Moolapattarai Intersection 


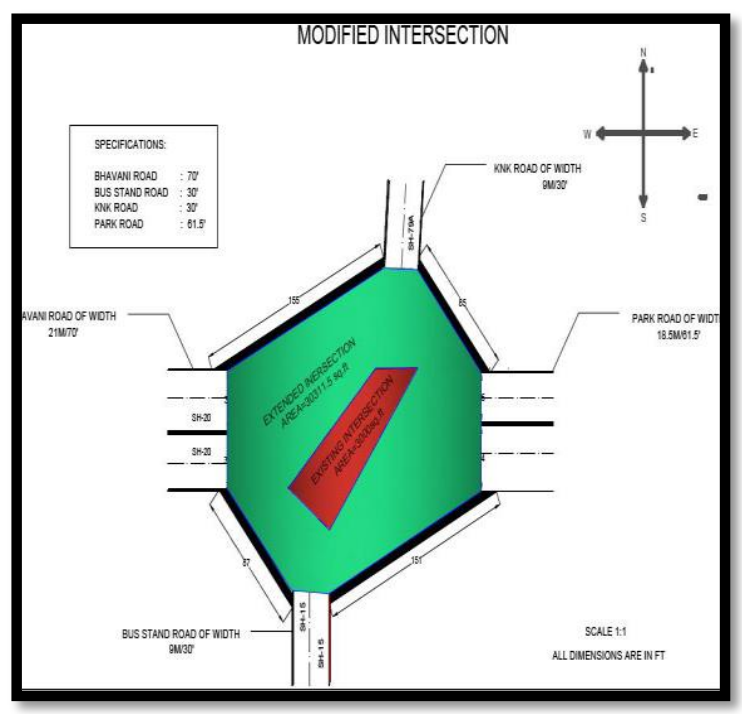

Figure 7.2 Area of Moolapattarai Intersection

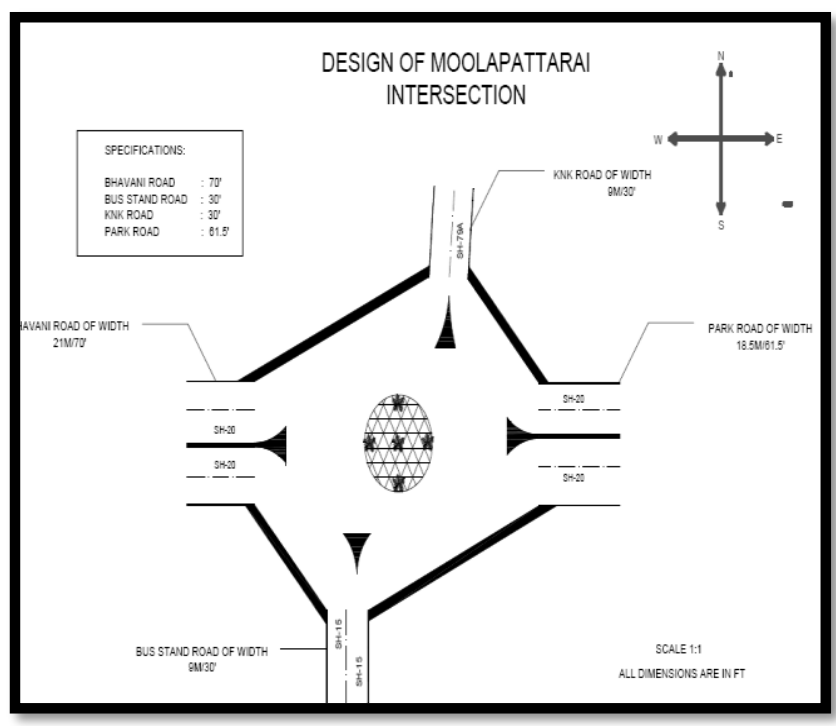

Figure 7.3 Design of Moolapattarai Intersection

\section{CONCLUSIONS}

The rapid growth of vehicles has become a major detrimental to road safety. This leads to more congestion at the intersections and increases the risk of accidents. Many intersections in urban areas have become accidents prone and the delay at such intersections was quite high. In order to reduce the risk of accidents and enhance the orderly movement of vehicles, it is very much essential to design the intersections. In this project, an intersection in Erode city, which is heavily crowded with vehicles, was designed and suitable measures are suggested. This design project can give a better suggestion for Moolapattarai intersection. 


\section{REFERENCES}

1. Dr. Alberto and M. Figueroa, “Modern Roundabout Geometric Design Guidelines,” WSDOT design manual, M 22.01.10.

2. Dr.L. R. Kadiyali, "Traffic Engineering and Transport Planning”, Khannan Publishers, New Delhi, 2009.

3. IRC 3:1983 "Dimensions and Weights of road design vehicles".

4. IRC SP-41:1994 "Guidelines for the design of At-grade intersections in Rural and Urban areas" and also used for PCU values.

5. IRC 64:1990 “Guidelines for Capacity of Road in Rural Areas, (First Edition)” published by The Indian Road Congress in 1990.

6. Tanveer, S. (2016). Application of Graph Theory in Representing and Modelling Traffic Control Problems. International Journal of Mathematics and Computer Applications Research (IJMCAR) ISSN (P), 2249-6955.

7. IRC 65:1976 "Recommended practice for Traffic Rotaries".

8. IRC 66:1976 "Recommended practice for sight distance on rural highways"

9. S. K. Khanna, C. E. G. Justo, "Highway Engineering”, Nem Chand \& Bros, Roorkee, India, 2011. 